\title{
PREPARANDO A PRIMAVERA: CONTRIBUIÇÕES PRELIMINARES PARA UMA CRÍTICA SUPERADORA À PEDAGOGIA DA INCLUSÃO ${ }^{1}$
}

\author{
Giovani Ferreira Bezerra ${ }^{2}$
}

\section{RESUMO}

Este texto tem caráter ensaístico. Visa-se apresentar reflexões e proposições, pautadas no materialismo histórico-dialético, sobre o movimento de inclusão escolar de alunos com deficiência e outras necessidades educacionais especiais na escola comum, tal como este vem se configurando, sobretudo, desde os anos de 1990, no bojo das demandas apresentadas pela própria sociedade do capital, ontologicamente excludente e segregadora. Propõe-se que a chamada Pedagogia da Inclusão seja analisada sem perder de vista os pressupostos da totalidade, historicidade e contradição, com vistas à sua crítica superadora. Palavras-chave: Materialismo histórico-dialético; Capitalismo; Educação e Inclusão escolar; Educação Especial; Pedagogia Histórico-Crítica.

\section{PREPARING THE SPRING: PRELIMINARY CONTRIBUTIONS TO A CRITICAL SURPASSING TO PEDAGOGY OF INCLUSION}

\begin{abstract}
This text has essayistic character. Aims to present reflections and proposals, grounded in Historical and Dialectical Materialism, on the movement of school inclusion of students with disabilities and other special needs in regular schools, as this is shaping up, especially since the 1990s, in the context of the demands presented by the capitalist society, ontologically excluding and segregating. It is proposed that the call Pedagogy of Inclusion be analyzed bearing in mind the assumptions of totality, historicity and contradiction, with a view to its surpassing criticism.

Keywords: Historical and Dialectical Materialism; Capitalism; Education and School Inclusion; Special Education; Historical-Critical Pedagogy.
\end{abstract}

\section{Prólogo: invocando as flores}

Este trabalho, resultante de minha dissertação de mestrado, surge como um desdobramento de estudos que já realizei sobre a temática inclusão, particularmente da inclusão escolar de alunos com deficiência intelectual (BEZERRA, 2012 ${ }^{3}$ ). O contato com o tema levou-me a adotar, progressivamente, uma postura crítica, por vezes combativa, em relação aos apelos inclusivistas das últimas décadas, quando se vai configurando, no Brasil, uma "pedagogia inclusiva", no bojo de uma sociedade neoliberal, perpassada pelos antagonismos de classe e concessões paliativas aos interesses populares. Os termos pedagogia inclusiva e/ou "pedagogia da inclusão", dos quais me utilizo como sinônimos ao longo do texto, têm aparecido com certa frequência na literatura referente à inserção de alunos com deficiência ou outras singularidades nas escolas comuns. 
Coloco as expressões pedagogia inclusiva e pedagogia da inclusão entre aspas apenas em sua primeira ocorrência, acima, para não poluir a explanação teórica, embora se pudesse assim destacá-las em todas as vezes que são aqui mencionadas. As aspas se justificam visto que a pedagogia inclusiva, bem como suas designações equivalentes, não constitui, efetivamente, uma pedagogia em sentido estrito. Mas tem sido denominada dessa forma por alguns autores e defensores da inclusão escolar, a fim de se chamar a atenção da sociedade e da escola para a necessidade de práticas educacionais acolhedoras, tolerantes e abertas às diferenças individuais, em particular àquelas decorrentes de deficiência física, sensorial e/ou intelectual. Com isso, o termo ganha uma dimensão de slogan sedutor, sendo incorporado ao senso comum educacional como uma proposta progressista e até mesmo revolucionária, não obstante derivada do ideário neoliberal.

Um rápido levantamento bibliográfico revela que as expressões pedagogia da inclusão e/ou pedagogia inclusiva aparecem citadas em fontes diversas. Esse é o caso, por exemplo, da revista Nova Escola, que, em matéria de 2002, explicitava recomendações sobre "[...] o que você [isto é, o professor-leitor] pode fazer para praticar uma pedagogia inclusiva" (ALENCAR, 2002, p. 36, grifo meu). Beyer (2010, p. 40) também cita o termo pedagogia inclusiva. Selau (2010, p. 70) alude à expressão pedagogia da inclusão, que também aparece em texto de Fontes (2002, p. 51). Oliveira e Poker (2002, p. 235, 237, $238,241,242$ ) citam, no mesmo trabalho, os termos pedagogia da inclusão e pedagogia inclusiva. Nessa direção, outros trabalhos ainda poderiam ser aqui arrolados, embora, para os propósitos deste ensaio, tais apontamentos sejam suficientes para demarcar o uso frequente e relativamente consensual do termo pedagogia da inclusão ou pedagogia inclusiva pelo discurso pedagógico ora hegemônico. Com semelhante jargão, anuncia-se, sobretudo, o ingresso de estudantes considerados público-alvo da educação especial ${ }^{4} \mathrm{em}$ classes comuns do ensino regular.

Por outro lado, a designação pedagogia da inclusão ou pedagogia inclusiva é por mim aqui utilizada no sentido de evidenciar sua íntima conexão com as demais "pedagogias" do aprender a aprender (DUARTE, 2001, 2008, 2010). Revigorando pressupostos do ideário escolanovista/construtivista, a pedagogia inclusiva tem apregoado e balizado a "inclusão" de alunos com deficiência nas escolas comuns, sob o mote do aprender a viver juntos (BEZERRA; ARAUJO, 2010, 2011), um dos "pilares" ideológicos que sustentam a versão contemporânea do lema aprender a aprender. Dessa perspectiva, tenho defendido que a pedagogia inclusiva é mais uma das manifestações assumidas pelas pedagogias do aprender a aprender, com a particularidade de enfatizar a escola que incorpora as diferenças humanas, estas interpretadas, principalmente, como resultado das distintas formas de desenvolvimento ontogenético.

$\mathrm{Na}$ atualidade, tais pedagogias referem-se mais a propostas ou linhas de ação do que a uma teoria da educação propriamente dita. Com caráter propagandístico, elas "[...] fundamentam as propostas educacionais nos âmbitos nacional e internacional [...] e, no limite, submetem o desenvolvimento humano à ordem do capital" (EIDT, 2010, p. 158). Como a mesma autora sintetiza,

O termo 'pedagogias do aprender a aprender' foi cunhado por Duarte (2001) e pode ser definido como um termo 'guarda-chuva', por reunir os traços essenciais de diferentes correntes pedagógicas, entre elas a Escola Nova, o Construtivismo, a Pedagogia das Competências e os estudos na linha do Professor Reflexivo (EIDT 2010, p. 158).

Perante o exposto, cumpre ressaltar, desde já, que este não é um texto contra o ingresso de pessoas com deficiência ou quaisquer outras singularidades nas escolas e Revista HISTEDBR On-line, Campinas, $n^{\circ}$ 68, p. 272-287, jun2016 - ISSN: 1676-2584 
classes comuns. Afinal, embora essa proposta, de caráter burguês, tenha sido gestada precipuamente a partir dos anos de 1990, com a reorganização do capital, "[...] este entendido como capital globalizado, neoliberal e até como pós-moderno" (CASSIN, 2008, p. 163), não se pode desconsiderar que o movimento pela inclusão escolar tem propiciado ganhos significativos para as relações humanas; sinalizando, de modo paradoxal, para o desenvolvimento mais livre e universal do gênero humano. Essas conquistas surgem como uma contradição inerente ao próprio modo de produção capitalista, que, ao desencadear o avanço das condições materiais e políticas, como estratégia de autopreservação, tem possibilitado a emergência de práticas educacionais e sociais potencialmente mais humanizadoras, ainda que persistam hegemônicas diversas formas de expropriação, alienação e barbárie.

No sentido considerado, a explanação subsequente não se constitui, pois, em um manifesto anti-inclusão. Recorrendo a Saviani (2009a, p. 34), atrevo-me a dizer que, como o citado autor, "[...] estou colocando-me diretamente no coração do político. Estou enunciando teses; isso significa posições, e posições polêmicas". Não a polêmica por si mesma, mas a polêmica como momento catártico, que objetiva o entendimento mais amplo da problemática levantada, na disputa por uma posição contra-hegemônica no cerne da produção científica sobre o assunto. Trata-se, como menciona Gramsci (1995, p. 31), de assumir “[...] um ponto de vista 'crítico', o único fecundo na pesquisa científica". E, assim, vislumbrar, no plano educacional, uma pedagogia que também seja crítica, desmistificada e emancipadora, em vez de meramente inclusivista. Nesse ponto, parece-me relevante esclarecer o que se entende por pedagogia crítica. Mais uma vez é Saviani (2003, p. 100) quem me inspira, ao afirmar que

[...] a pedagogia crítica implica a clareza dos determinantes sociais da educação, a compreensão do grau em que as contradições da sociedade marcam a educação e, consequentemente, como é preciso se posicionar diante dessas contradições e desenredar a educação das visões ambíguas, para perceber claramente qual é a direção que cabe imprimir à questão educacional.

Os dizeres de Saviani (2003) medeiam a forma como me posiciono a respeito da pedagogia inclusiva e suas tematizações contemporâneas, à medida que eu tenho procurado desvelar ambiguidades e contradições por ela engendradas (BEZERRA, 2012). Nessa démarche, venho adotando como mote um pensamento de Karl Marx, exposto na Introdução à Crítica da Filosofia do Direito de Hegel. Nesse texto, originalmente publicado em 1844, menciona o filósofo que "A crítica colheu nas cadeias as flores imaginárias, não para que o homem suporte as cadeias sem fantasia ou sem consolação, mas para que lance fora as cadeias e colha a flor viva" (MARX, 2008, p. 6). Em outras palavras, quero assinalar, a partir das considerações metafóricas de Marx, que a crítica ora objetivada não é, também, partidária do imobilismo, nem quer reproduzir o desânimo, o desalento e o conformismo. Antes, rejeitando as teses que endossam o falso poder equalizador da escola e as inversões ideológicas decorrentes desse posicionamento, ainda tão disseminando entre nós, pretendo suscitar um debate mais realista e desfetichizado sobre a pedagogia inclusiva. Minha intenção é contribuir, mesmo que de modo bastante preliminar e incipiente, na proposição de outros caminhos para a educação escolar de pessoas com deficiência, caminhos esses que, em linguagem poética, aproximem-nos cada vez mais da primavera.

Entendo que, na atual conjuntura, sem esse debate, ele mesmo uma forma de crítica-ação acerca da pedagogia inclusiva e suas possibilidade de superação, pouco se 
poderá avançar na luta por uma sociedade e educação revolucionárias, seja para pessoas com e/ou sem deficiência. Nas condições sociais e educacionais aviltadas da contemporaneidade, torna-se um desafio resgatar o potencial transformador da análise teórica, porquanto, como assinala Alves (2004, p. 162-163, grifo meu), "O domínio da teoria se constitui em frente de ação privilegiada para iluminar e direcionar a prática política, configurando-a estrategicamente e definindo-a taticamente, além de já representar o seu desencadeamento". É com base em semelhante concepção e nos pressupostos supramencionados que esboço as reflexões seguintes, com o ardor daqueles que desejam a primavera, mas ainda perpassado pelas limitações daqueles que enfrentam o inverno rigoroso, quando os horizontes parecem tolhidos; as forças, debilitadas. Todavia, também acredito que o inverno seja um tempo de espera, reflexão e preparação. É um intermezzo entre velho e o novo. Por isso, não quero ceder ao pessimismo ingênuo e desconcertante, mas, como os povos antigos do Hemisfério Norte, enquanto as rajadas de vento frio batem à minha janela e a neve cobre a paisagem, comprometendo a visibilidade, almejo aproveitar esse tempo preparando a primavera. Isso significa que, doravante, lançome ao trabalho da crítica superadora à pedagogia da inclusão.

\section{Intermezzo: preparando a primavera}

É corrente o discurso em defesa da escola e ensino de qualidade para todos, com atenção às necessidades educacionais especiais de cada estudante. Não obstante, à luz de uma análise crítica e radical, contanto que se entenda radicalidade no sentido atribuído por Marx (2008) e Saviani (2002), esse discurso não se sustenta. A complexidade do trabalho educativo envolvendo alunos com deficiência fica escamoteada pela retórica que celebra e fetichiza a diversidade, além de depositar no "entrosamento" da equipe escolar a solução pragmática para as dificuldades docentes. Entre outros aspectos, essas características levam-me a conceber a pedagogia da inclusão como mais uma das pedagogias erigidas sob a perspectiva neoescolanovista, que revigora o lema aprender a aprender, com destaque especial, no caso estudado, para o princípio valorativo do aprender a viver junto com o outro, aprender a conviver. Desse modo, é possível relacionar os apelos inclusivistas ao movimento global, incorporado à agenda política brasileira, em defesa da escola inclusiva, da escola para todos, que "acolhe" alunos com ou sem deficiência. Movimento que, todavia, não põe em risco a reprodução sociometabólica do capital, por pautar-se em uma compreensão reformista e idealizada da sociedade, cumprindo a função de abrandar as tensões sociais que eclodem nos últimos anos, haja vista a crise financeira estrutural que atinge o capitalismo contemporâneo.

A materialização da escola inclusiva, enquanto universalização precária e pouco dispendiosa do ensino, revela, na essência, a primazia dos interesses de mercado. Ao mesmo tempo, pela sua aparência democrática e equalizadora das diferenças individuais, essa escola assume papel estratégico como justificativa ideológica à manutenção do capitalismo e de suas "virtudes". Nessas condições, a inclusão escolar, como apregoada por organismos internacionais, pelo discurso oficial do governo brasileiro e pela imprensa pedagógica dominante em nosso país, não só colabora para a perpetuação do capital e suas desigualdades, como lhe é necessária na conjuntura hodiernamente delineada pela hegemonia do modelo toyotista de acumulação produtiva; balizado, no plano superestrutural, pela teoria do capital humano - esta refuncionalizada de acordo com as demandas do neoprodutivismo e da empregabilidade, que reclamam, no processo produtivo, qualidade total e trabalhadores flexíveis - e pelo neoliberalismo, em suas interfaces com as concepções relativistas da pós-modernidade ${ }^{5}$. Concepções que tornam a 
diferença, a deficiência e as singularidades individuais um fetiche a ser venerado, pelo que se dissolvem, nas teorizações pós-modernas e neoliberais, as lutas de classe, os antagonismos entre capital e trabalho e as formas de exploração prevalecentes na sociedade produtora de mercadorias.

Ora, mas se este pensamento corresponde à dinâmica da realidade contemporânea, se é confirmado pela práxis humana que se objetiva mediante a materialidade das relações sociais de produção, engendradas pelo capitalismo monopolista, deparamo-nos, então, com este desafio: revolucionar essas circunstâncias e lutar por sua transformação, a menos que concordemos com sua continuidade. Esse empreendimento - é preciso reconhecer - não é, contudo, tarefa fácil, pois, como homens deste tempo e desta sociedade, não estamos além da história, mas somos, também, produtos dessas circunstâncias. Não estamos, portanto, imunes ao desalento, à capitulação à ideologia neoliberal e pós-moderna, à sedução das flores ilusórias. Se não temos essa compreensão sobre os limites que nos cercam, incorremos mais facilmente no idealismo e no pragmatismo, tal como revela a pedagogia da inclusão, ao objetivar-se respaldada pelo ideário educacional burguês. E corremos o risco de endossar perspectivas reacionárias e conservadoras, não obstante acreditarmo-nos partícipes de um processo revolucionário. Lembro que Saviani (2009a, p. 77) sempre nos alertou para o fato de que "[...] acreditar que estão dadas, nesta sociedade, as condições para o exercício pleno da prática educativa é assumir uma atitude idealista”. Essa atitude só cabe, pois, às pedagogias que não estão comprometidas, em seu núcleo teórico-prático, com a superação da sociedade de classes e suas formas burguesas de educação, caracterizadas pelo aviltamento do saber elaborado para a grande maioria dos indivíduos, alienados das realizações humanas mais avançadas, tanto materiais como intelectuais.

Tomar consciência dos limites históricos à ação revolucionária, nas circunstâncias atuais, bem como pugnar com o idealismo e a mistificação no trato das questões educacionais, sobretudo quando falamos em inclusão escolar de pessoas com deficiência, não significa, porém, que nada nos é permitido fazer. Nessa linha de raciocínio, compreende-se que a crítica à escola inclusiva não se esgota na dimensão críticoreprodutivista (SAVIANI, 2009a). Consoante ao pensamento marxiano, se "Por um lado, é necessário modificar as condições sociais para criar um novo sistema de ensino; por outro, falta um sistema de ensino novo para poder modificar as condições sociais. Consequentemente é necessário partir da situação atual" (MARX, 2011, p. 138). Em termos mais específicos, a situação atual permite que se entenda a categoria de inclusão escolar e social como uma concessão contraditoriamente forjada pelo avanço das condições materiais e políticas engendradas pelo próprio capital. Este, na busca por estratégias de autopreservação e justificação ideológica, tem possibilitado, sob o signo da contradição, a emergência de práticas educacionais e sociais mais humanizadoras. Logo, é preciso que tais práticas sejam cada vez mais socializadas e ampliadas para toda a população, como parte de um projeto revolucionário alternativo, distinto do que ora está hegemônico.

A epígrafe marxiana, registrada na parte introdutória, é, pois, um convite à análise crítica como ponto de partida e fundamento para o engajamento na transformação dessas mesmas condições que, sob o capital, oferecem resistência ao trabalho revolucionário. $\mathrm{Na}$ direção do exposto, embora se referindo a outro contexto, que não o das políticas de inclusão escolar, há uma passagem de Gentili (2005, p. 46) muito inspiradora para reforçar o que estou querendo dizer. Nas palavras do autor, "[...] nos tempos de penumbra, a crítica teórica pode ajudar a iluminar alternativas e fortalecer esperanças"; isso se, revisitando Marx (2008, p. 8, grifos no original), considerarmos também que "A crítica já não é fim em si, mas apenas um meio; a indignação é o seu pathos essencial, e a denúncia a sua 
principal tarefa". Foi nessa perspectiva da crítica como instrumento para mediar a transformação da realidade, suscitando alternativas contra-hegemônicas à ordem sociometabólica vigente, que empreendi a análise da pedagogia inclusiva e seus pressupostos em minha dissertação (BEZERRA, 2012). Entendo que, dessa forma, o posicionamento crítico pode colaborar para enfrentar o poder fictício atribuído à escola dita inclusiva, sem que isso signifique, outra vez me valendo dos termos de Saviani (2002), descambar para o pessimismo ou para o otimismo, ambos ingênuos.

Antes, trata-se de aproximarmo-nos do entusiasmo crítico (SAVIANI, 2002), pelo qual os condicionantes objetivos da sociedade nos são conhecidos em suas múltiplas dimensões e, por isso mesmo, passíveis de serem enfrentados, teórica e praticamente, apesar da coerção material exercida pelas forças produtivas ainda organizadas segundo o modo de produção capitalista. Como aprendemos de Marx e Engels (2007), não podemos olvidar que os homens são, também, produtores das circunstâncias, são os agentes vivos da história. É nesse sentido que vislumbro um potencial revolucionário a partir da pedagogia da inclusão, contanto que esta seja compreendida como proposta burguesa que se quer superar, por incorporação dialética, rumo a uma sociedade socialista. Ao mencionar as pedagogias do aprender a aprender - entre as quais eu englobei, neste trabalho, a pedagogia inclusiva - Duarte (2008, p. 217) menciona que uma pedagogia revolucionária, de base marxista, "[...] deve superar por incorporação todas as pedagogias burguesas e, nesse processo, deverá distinguir o que exista de avançado nessas pedagogias e possa ser incorporada a outra ideologia" ${ }^{6}$.

No meu entender, a inclusão escolar de alunos com deficiência pode desempenhar um papel estratégico na agudização das contradições sociais hoje existentes, porquanto põe em perspectiva a necessidade de nova organização social e escolar, para além do capital. Cabe lembrar que a abertura da escola para todos tende a desencadear, pela via da contradição, processos transformadores. Na concepção de Sanfelice (1989, p.36),

Quanto mais se democratizar a oportunidade de acesso à educação formal e quanto mais se criar condições para que ela garanta sua especificidade, menos se estará atendendo aos interesses burgueses que já não podem executar o que discursam: não podem construir uma sociedade livre, igual e fraterna, nem podem construir uma escola democrática e socializadora dos conhecimentos socialmente disponíveis a todas as clientelas que essa sociedade comporta.

Logo, embora estejamos imersos em um sistema capitalista, não se pode dizer, que, no bojo dos processos educacionais inclusivos das últimas décadas, inexistam potencialidades revolucionárias. Estas, como dizia Gramsci (1995), se ainda não são $a$ transformação material da realidade vivenciada, também não deixam de ser uma realidade, pois, se os homens as vislumbram, é porque essas possibilidades já existem concretamente, embora alienadas da maioria dos indivíduos; ou, de outro modo, estão em vias de se efetivar. Na clássica formulação marxiana, “[...] a humanidade não se propõe nunca senão os problemas que ela pode resolver, pois, aprofundando a análise, ver-se-á sempre que o próprio problema só se apresenta quando as condições materiais para resolvê-lo existem ou estão em vias de existir" (MARX, 1989, p. 233). E, como complementa Gramsci (1995, p. 47, grifo meu), "O homem, neste sentido, é vontade concreta: isto é, aplicação efetiva do querer abstrato ou do impulso vital aos meios concretos que realizam esta vontade"; sendo, portanto, como ser genérico, capaz de revolucionar intencionalmente os limites de sua vida, a fim de dar à própria existência os contornos mais livres e universais possíveis. 
O excerto gramsciano sinaliza para o entendimento de que não basta somente alardear, hoje, a existência de possibilidades objetivas e condições políticas favoráveis à promoção de propostas educacionais consideradas inclusivas. É também fundamental o enfrentamento das relações de dominação e alienação capitalistas que se insinuam nessas propostas, mediante discursos aparentemente transformadores. Apenas "[...] a existência das condições objetivas - ou possibilidade, ou liberdade - ainda não é suficiente: é necessário 'conhecê-las' e saber utilizá-las. Querer utilizá-las” (GRAMSCI, 1995, p. 47). Por certo, isso passa pelo constante aprofundamento teórico, objetivado em um fazer pedagógico revolucionário, comprometido com as necessidades do gênero humano, entre estas aquelas apresentadas pelas pessoas com deficiência ou outras singularidades.

Como enfatiza Barroco (2007a, p. 375, 384, 270), embasada pelas proposições marxistas do psicólogo bielorruso L. S. Vigotski, "A causa, se assim se pode dizer, é pela emancipação humana"; "[...] pela humanização do homem, de todo e qualquer homem"; "[...] e não somente de um ou outro segmento da sociedade", devendo-se olhar com cuidado os princípios da propalada educação inclusiva. Segundo a mesma autora, "Estes, como pode ser identificado em diferentes publicações, são legítimos. Todavia, fica difícil pensar em levá-los às últimas consequências mantendo-se a sociedade de classes, tal como se tem hoje" (BARROCO, 2007a, p. 375). Não cabe, porém, retroceder na história, segregando os alunos com deficiência ou outras "diferenças" em instituições que os privem da apropriação do saber elaborado, da participação social mais ampla possível e da fruição do que de mais avançado o gênero humano já conquistou em suas realizações materiais e intelectuais. Hoje, a sociedade dispõe (ou está prestes a dispor) de recursos científicotecnológicos e conhecimentos didático-pedagógicos avançados, que permitam o ingresso de todos na escola. Falta a socialização dessas conquistas, em vez de sua apropriação por pequena parcela da população que pode comprar tais mercadorias. Assim sendo, entendo que, neste momento, do ponto de vista ofensivo, cumpre encampar "[...] a defesa intransigente de uma educação estatal ${ }^{7}$, gratuita, laica, obrigatória e universal para todas as crianças" (LOMBARDI, 2008, p. 21).

O lugar propício para a oferta dessa educação, de caráter formal, não há de ser outro, portanto, senão o espaço da escola comum, público-estatal, gratuita e não confessional, aberta para todos, mas em condições que permitam conciliar momentos de atendimento educacional individualizado e coletivo, com a mediação docente, especializada ou não, conforme requerer o percurso de desenvolvimento ontogenético de cada estudante. Para tanto, essa escola, a ser construída nos espaços da contradição entre o capitalismo e o socialismo, terá que ter repensada a organização do trabalho didático e seu próprio arranjo físico (ALVES, 2004); possibilitando, assim, condições estruturais e didático-pedagógicas para que o atendimento educacional especializado aos alunos com deficiência ocorra sempre que necessário, sem interrupções, com os instrumentos, profissionais e recursos demandados; e não apenas em um momento pontual, no contraturno, como tem sido. Como é importante ressaltar, permanece o compromisso da escola com a transmissão do saber objetivo para todos, aspecto que, aliás, lhe confere especificidade institucional. Tampouco se pretende abdicar, na perspectiva aqui esposada, do suporte de outras instituições que cumprem o papel clínico-terapêutico, distinto do trabalho pedagógico, mas essencial para o pleno desenvolvimento dos indivíduos com deficiência. Nessa direção, Sanfelice (1989), ao discutir sobre o ingresso de distintas clientelas na escola pública e gratuita, inclusive os alunos com deficiência intelectual, sublinha que 
Não se trata de a escola substituir outras instituições que com certeza terão que trabalhar também com os 'deficientes mentais', mas o que ela realmente pode garantir é o acesso aos conhecimentos sistematizados socialmente disponíveis, independente do ponto de partida que se fizer necessário para o início da ação pedagógica (SANFELICE, 1989, 36, grifo meu).

Desse ângulo, a abertura da escola para alunos com deficiência implica admitir que estratégias diferenciadas e metodologias específicas, pelo menos no ponto de partida, façam parte da ação pedagógica, "[...] para que possamos obter uma igualdade de oportunidades efetivas"; em vez de se promover, no que tange a esses estudantes, sua "[...] fictícia aceitação, em suposta condição de igualdade e que é apenas formalmente democrática, mas de fato discriminadora" (SANFELICE, 1989, p. 36). À luz de tais ponderações, é válido argumentar que a democratização da escola, se quisermos ir além de sua universalização precária, não pode ser entendida de forma dogmática, panfletária e radicalista, no sentido de se impingir a presença compulsória de todos os alunos, em todos os momentos, nas salas de aula comum, com a imposição de uma homogeneidade forçada no ponto de partida. Penso sim que seja de vital importância a defesa de uma escola unitária, em tempo integral, que se oponha à polaridade entre escola especial e escola comum e/ou sala de recursos multifuncionais e sala de aula comum. No mesmo espaço, a escola unitária pressupõe formas de ensino individualizadas e diferenciadas, mas também não se furta à proposição do estudo coletivo entre todos os estudantes. Seu fundamento é o vínculo orgânico entre a educação especial e a educação geral, como nova síntese superadora.

Para caminharmos na direção dessa síntese, não podemos abdicar dos conhecimentos que, historicamente produzidos no bojo da ciência burguesa, contribuam para a definição de procedimentos didático-metodológicos para orientar o ensino de alunos com deficiência. A pedagogia da inclusão, no cenário da educação burguesa, tem desconsiderado essa premissa, na medida em que nega o legado da pedagogia especial. A pedagogia da inclusão emerge, pois, como uma pedagogia das superfícies, das aparências, opondo-se à reflexão em profundidade (BEZERRA; ARAUJO, 2011; SAVIANI, 2002). Para ela, têm valor preponderante exemplos e experiências pessoais de e sobre a escola inclusiva, carregados de afetividade e teor pragmático. Nessa ordem das ideias, defendo que, para o avanço das discussões e para a reorganização do trabalho didático, no intuito de se atender aos alunos com deficiência, põe-se a necessidade de estudarmos os autores clássicos da educação especial, nos cursos de formação docente inicial e continuada. Para mediar o desenvolvimento dos estudantes nessa condição ontogenética, os professores não podem dispor como fonte precípua de seu planejamento e fonte de pesquisas apenas de "manuais" e bibliografias que enalteçam o privilégio de estar com o outro, sem, contudo, se aprofundar na discussão das especificidades teórico-metodológicas reclamadas nesses casos.

Afinal, sem a apreensão histórica e totalizante dos fundamentos clássicos da educação especial, entendidos como referência a ser superada por incorporação dialética, há o perigo de incorrermos no espontaneísmo e de tomarmos a afetividade como o principal parâmetro da ação pedagógica. Penso que caberia, sob as lentes da Pedagogia Histórico-Crítica, empreender o levantamento e estudo sistemático dos métodos que caracterizaram o ensino de pessoas com deficiência ao longo da história, para, a partir deles, repensarmos a organização do trabalho didático em tempos de inclusão escolar. Tratar-se-ia de compor uma história dos métodos pedagógicos especiais, compilada de modo orgânico e analítico-sintética, para se perceber o que pode ser considerado 
anacrônico na atualidade e o que pode fundamentar, ainda, as intervenções pedagógicas no ensino de alunos com deficiência; bem como quais recursos tecnológicos já existentes poderiam ser incorporados para o avanço desse legado.

Semelhante proposta se justifica porque a escola para todos, balizada pela pedagogia inclusiva, tem representado uma ruptura abrupta com a educação especial. Desse modo, esse "modelo" de escola é construído sobre o imediatismo do presente, baseado na empiria cotidiana, ou, como dizia Vygotski (1997), erige-se sobre a areia, porquanto prescinde de fundamentação teórico-metodológica. A escola inclusiva, nessas condições, caminha na contramão da história, pois os homens nunca partem senão daquilo que legam do passado, das gerações anteriores. Em outras palavras, penso que não podemos nos objetivar, na práxis social, a não ser mediados pela apropriação das objetivações materiais e intelectuais precedentes, as quais são reelaboradas nesse processo. Assim avança a humanidade. Como asseguram Marx e Engels (2007, p. 46-47, grifo meu),

\begin{abstract}
A história não é senão a sucessão das diferentes gerações, cada uma das quais explora os materiais, os capitais, as forças produtivas que lhe são transmitidas pelas gerações precedentes; assim sendo, cada geração, por um lado, continua o modo de atividade que lhe é transmitido, mas em circunstâncias radicalmente transformadas e, por outro lado, ela modifica as circunstâncias entregando-se a uma atividade radicalmente diferente.
\end{abstract}

Ao perder de vista as categorias de totalidade, contradição, mediação e historicidade, a pedagogia inclusiva e sua proposta de escola para todos secundariza a socialização dos conhecimentos científicos historicamente produzidos pelo coletivo dos homens; além de não levar em conta a contribuição das metodologias, dos materiais, dos "capitais" e das forças produtivas herdados da pedagogia especial, para estabelecer uma analogia ao pensamento marxiano. Em vez disso, a pedagogia da inclusão desconsidera que a atividade educativa, caso deseje se apresentar como revolucionária e queira superar o passado, não pode prescindir da historicidade, não pode começar do "vazio", da especulação apenas. Na realidade, é necessário que parta de práticas transmitidas historicamente para, então, continuar aquela mesma atividade, isto é, a educação de pessoas com e sem deficiência; porém, "em circunstâncias radicalmente transformadas". O intuito não é, portanto, repetir o passado, mas sim imprimir outro curso ao presente, qualitativamente superior, mediante a incorporação dialética de determinadas premissas e a negação de outras, que não mais respondam às necessidades históricas do tempo atual. Nessa acepção é que a praxis educativa pode, em termos dialéticos, modificar essas circunstâncias legadas do momento histórico anterior, entregando-se a uma atividade radicalmente diferente, à medida que toma conhecimento desse legado e o (re)elabora.

O que estou dizendo é comprovado com a leitura deste trecho de Vygotski (1997), bastante esclarecedor para se compreender a necessidade de referenciais teórico-práticos mais consequentes na educação de pessoas com deficiência, sem se desconsiderar a educação especial, mas ressignificando-a no campo da pedagogia geral. Para o autor:

En el terreno práctico, en el terreno de la educación - como hemos intentado exponerlo - la defectología ${ }^{8}$ se encuentra ante tareas cuya solución demanda un trabajo creativo, de organización de formas especiales. Para resolver tales o cuales problemas de la defectología es preciso encontrar un sólido fundamento, tanto para la teoría como para la práctica. A fin de no construir sobre arena, a fin de evitar el 
empirismo ecléctico y superficial, que la distinguía en el pasado, a fin abandonar la pedagogía hospitalario-medicamentosa y pasar a una pedagogía creativamente positiva, la defectología debe apoyarse en el fundamento filosófico del materialista dialéctico sobre el cual se construye nuestra pedagogía general, y en el fundamento social sobre el cual se construye nuestra educación social. Es éste, precisamente, el problema de nuestra defectología" (VYGOTSKI, 1997, p. 36-37, grifo meu).

Mediante as considerações expostas acima, a convocatória de Vygotski (1997) parece ainda encontrar repercussão nos desafios que temos pela frente, quanto à necessária vinculação a ser estabelecida, teórica e praticamente, entre o legado da educação especial e a educação geral; muito embora suas palavras tenham sido proferidas no começo do século XX, nas fronteiras da Rússia pós-revolucionária. Segundo exprime o autor,

La tarea consiste en vincular la pedagogía de la infancia deficiente (pedagogía de sordos, ciegos, oligrofrénicos, etc.) con los principios y métodos generales de la educación social; encontrar tal sistema, que permita ligar orgánicamente la pedagogía especial con la pedagogía de la infancia normal. Nos aguarda un gran trabajo creativo para reestructurar nuestra escuela sobre la base de nuevos principios. Debemos esbozar las líneas básicas o, para decirlo con más exactitud, los puntos de partida, para esa labor (VYGOTSKI, 1997, p. 59, grifo meu).

Assim, com base nas formulações sobreditas, meu entendimento é que não basta somente reconhecer que há uma "diferença" ou um curso diferenciado no desenvolvimento ontogenético dos estudantes com deficiência; tampouco transferir, exclusivamente, a preocupação com as singularidades desse desenvolvimento para momentos reservados do Atendimento Educacional Especializado (AEE), deslocado, no tempo e no espaço, da sala de aula comum ${ }^{9}$. Há que se objetivar uma proposta educacional coerente, abrangendo todas as situações educacionais vivenciadas pelos estudantes, a fim de que se vislumbre, com o desenrolar do processo pedagógico, uma prática docente democrática. Daí ser indispensável pensar, também, na ampliação da competência teórico-prática do professor, a fim de tornar sua ação a mais comprometida possível com o pleno desenvolvimento dos alunos com deficiência. Precisamos, nesse aspecto, de perseguir a unidade dialética entre a formação técnica, especializada, e o compromisso político com a educação, de modo a não perdemos de vista a função especificamente pedagógica da escola, que demanda a transmissão-assimilação do conhecimento científico para a produção da humanidade em cada indivíduo singular. A discussão suscita repensar, pois, a própria formação do pedagogo e demais licenciaturas.

Dessa ótica, a educação especial não pode ser apenas mais uma "disciplina" a figurar no currículo universitário, mas sim uma temática que perpasse todas as outras disciplinas curriculares: a Didática, a Psicologia da Educação, as Metodologias de Ensino, o Estágio Supervisionado e assim por diante. Ademais, a formação dos professores para atuar na modalidade da educação especial carece de ser redimensionada, com a contribuição dos diferentes pesquisadores, professores e outros profissionais afins, porquanto a formação especializada, nessa área, segue "desguarnecida" e indefinida (SAVIANI, 2009b). Reivindicar das instâncias governamentais a prerrogativa de um espaço específico e unitário para mediar tal formação pode ser uma importante estratégia de luta para reverter esse quadro. Cursos aligeirados de pós-graduação ou iniciativas 
esparsas de formação continuada dificultam a definição de estratégias mais orgânicas para o atendimento educacional especializado no interior das escolas comuns, corroborando práticas excludentes e segregadoras, haja vista que ficam negligenciadas as particularidades ontogenéticas manifestadas, concretamente, pelos alunos com deficiência.

Indo mais além, no cerne das proposições políticas e educacionais levantadas, o debate referente à escola inclusiva, do ponto de vista contra-hegemônico, também precisa suscitar um questionamento cada vez mais agudo acerca da organização social capitalista que move o país, refletida no aviltamento das condições do trabalho docente. Do contrário, permaneceremos na fase romântica da inclusão escolar, que superestima os "poderes" da escola, vista como um espaço harmoniosamente "includente", por si só corretor das desigualdades socioeconômicas. Nessa conjuntura, entendo que a convocatória pelo ingresso e permanência de alunos com deficiência ou quaisquer outras singularidades nas escolas comuns deve alinhar-se, reciprocamente, ao combate da sociedade que (re)produz essa lógica excludente, mediante nosso engajamento em prol da formulação coletiva de um projeto político-pedagógico oposto à ordem capitalista; capaz de propiciar a todos, com ou sem deficiência, com ou sem uma "diferença", a fruição plena das riquezas materiais e intelectuais historicamente produzidas e acumuladas pela humanidade, sem apelos "inclusivistas" e medidas paliativas. Como diz Barroco (2007b, p. 160), "Se esse empenho parece utópico, ainda assim constitui-se em um norte para o qual seguir. Mas essa luta torna-se estéril se não for considerada a lógica da sociedade de classes capitalista". Por isso a necessidade de compreendermos tal (i)lógica e seus desdobramentos na educação e sociedade contemporâneas - quando proliferam tantos slogans inclusivistas - para a ela nos contrapormos objetivamente, na busca pelas flores vivas. Talvez, nas condições atuais, essa seja a melhor forma de enfrentarmos o inverno rigoroso que nos rodeia, (re)unindo forças e mantendo o corpo aquecido, enquanto preparamos a primavera...

\section{Epílogo: para terminar falando de flores...}

Para concluir provisoriamente este texto, complementando as afirmações supramencionadas, quero reafirmar que o objetivo de incluir alunos com deficiência, entre outras particularidades, posto como uma nova função atribuída à escola comum, no momento histórico atual, não pode, todavia, ficar limitado ao contexto escolar, em bases pseudodemocrática e reducionistas. Esse objetivo, para os que miram o horizonte revolucionário, há de ter também o papel de suscitar a renovação do compromisso técnico e da competência política (SAVIANI, 2003) com a emancipação universal de todos os homens, com ou sem deficiência; de tal forma que se busque "[...] criar um sistema de educação que lhes assegure um desenvolvimento multilateral e harmonioso que dê a cada um a possibilidade de participar enquanto criador em todas as manifestações de vida humana" (LEONTIEV, 1978, p. 284, grifo meu). Vale dizer, então, que o entendimento prevalecente deixado por este ensaio é o de que o princípio humano-genérico não pode ficar obliterado nas discussões sobre "inclusão" a serem travadas no país, contanto que se almeje divisar outro projeto de sociedade e de educação. Dessa perspectiva, cumpre alertar que nem toda diferenciação é, em si mesma, excludente, e que a igualdade pode também ser discriminadora: lição que devemos levar para os próximos decênios deste século, se quisermos alcançar, de fato, algum avanço na proposta de inclusão escolar. o conjunto dessas reflexões, por ora apenas esboçadas, pode ser um ponto de partida para mediar o entendimento acerca dos limites e potencialidades inerentes às proposições inclusivistas na atual sociedade de classes; especialmente quando o intuito é atingir, como ponto de 
chegada, condições sociais e pedagógicas revolucionadas, na direção das palavras enunciadas por Marx (2011).

Sozinhos, não podemos, certamente, realizar essa travessia de um ponto a outro. $\mathrm{Na}$ acepção de Sanfelice (1989, p. 36), é pela ação orgânica dos educadores que defendem a escola pública, gratuita e de boa qualidade para todos que se "poderá converter um discurso inconsequente [como tem sido o discurso inclusivista] em prática progressista e transformadora do real”. A concretização dessa escola, pública, gratuita, unitária, capaz de atender a todos os estudantes, conforme suas necessidades educacionais, e de responder às novas demandas didático-pedagógicas que lhe são postas, como instituição formal de ensino, haverá, portanto, de ser consequência de esforços coletivos. Ou seja, "[...] não poderá ser produto da ação de um intelectual solitário, mas sim, e necessariamente, da atuação coletiva e combinada de muitos especialistas, educadores ou não, que coloquem a educação no centro de suas preocupações" (ALVES, 2004, p. 248). Nesse sentido, urge retomar o debate plural e democrático sobre os rumos da inclusão escolar no país, com a participação de toda a comunidade científica, dos sistemas de ensino, docentes, gestores, pessoas com deficiência, seus familiares, segmentos políticos, universidades, instituições com atuação em educação especial, entre outros envolvidos com o assunto.

Concebido dessa forma, tal debate, objetivado em ações e proposições teóricopráticas, poderá provocar o acirramento estratégico das contradições apresentadas pela pedagogia inclusiva, à medida que estas puderem ser conhecidas em suas múltiplas relações com a base material capitalista, constituindo-se em forças catalisadoras para a emergência da flor viva. Em linguagem metafórica, ouso dizer que a chegada da primavera, com suas esperanças renovadas, passa também, e não apenas, por esse caminho, cujas trilhas ainda precisam ser melhor exploradas em pesquisas futuras. Daí que, ao finalizar estas reflexões, eu me sinta tão perto e, ao mesmo temo, tão longe da flor viva. Perto, porque tenho buscado, pela mediação da análise, aproximar-me da totalidade concreta, no que se refere à apreensão teórica do fenômeno inclusão escolar de pessoas com deficiência. Mas tão longe, ante a necessidade de se avançar para além da crítica, rumo à atividade revolucionária, à atividade prático-crítica, como menciona Marx (2007), em sua primeira tese sobre Feuerbach. Por ora, considerando o momento histórico tensivo em que temos (sobre)vivido, parece-me sensato considerar esta máxima do revolucionário chinês Mao Tsé-Tung, a saber: "Deixai que as flores desabrochem e que floresçam as discussões"10. Assim espero, fazendo votos de que minhas reflexões, aqui apenas delineadas, possam se juntar às ponderações daqueles que também têm se empenhado para diminuir a distância a qual ainda nos separa das flores vivas. E que, desse modo, pelos caminhos outrora tristes e secos em virtude do prolongado inverno, brotem os cravos vermelhos com todo o vigor primaveril - arautos de um novo tempo...

\section{Referências}

ALENCAR, Marcelo. Incluir é derrubar preconceitos. Nova Escola: a revista do professor, São Paulo, ano xvii, n. 152, p. 36-37, maio 2002.

ALVES, Gilberto Luiz. A produção escola pública contemporânea. 2. ed. Campinas: Autores Associados; Campo Grande: Ed. UFMS, 2004.

BARROCO, Sonia Mari Shima. A educação especial do novo homem soviético e a Psicologia de L. S. Vigotski: implicações e contribuições para a psicologia e a educação 
atuais. 2007. 414 f. Tese (Doutorado em Educação Escolar) - Faculdade de Ciências e Letras, Universidade Estadual Paulista Júlio de Mesquita Filho, Araraquara, 2007a. Disponível em: <http://www.dominiopublico.gov.br/download/texto/cp042915.pdf>. Acesso em: 22 fev. 2010.

Psicologia e Educação: da inclusão e exclusão ou da exceção e da regra. In: MEIRA, Maria Eugênia Melillo; FACCI, Marilda Gonçalves Dias (Orgs.). Psicologia Histórico-Cultural: contribuições para o encontro entre a subjetividade e a educação. São Paulo: Caso do Psicólogo, 2007b. p. 157-184.

BEYER, Hugo Otto. Inclusão e avaliação na escola: de alunos com necessidades educacionais especiais. 3. ed. Porto Alegre: Mediação, 2010.

BEZERRA, Giovani Ferreira. Enquanto não brotam as flores vivas: crítica à pedagogia da inclusão. 2012. 270f. Dissertação (Mestrado em Educação) - Universidade Estadual de Mato Grosso do Sul, Unidade Universitária de Paranaíba, 2012.

BEZERRA, Giovani Ferreira; ARAUJO, Doracina Aparecida de Castro. As aparências enganam: a pretexto de uma crítica radical sobre o ideário inclusivista. Educere et Educare - Revista de Educação, Cascavel, v. 05, n. 09, p. 253-266, jan./jun. 2010. Disponível em: <http://erevista.unioeste.br/index.php/educereeteducare/article/view/2690>. Acesso em: $21 \mathrm{abr}$. 2011.

De volta à teoria da curvatura da vara: a deficiência intelectual na escola inclusiva. Educação em Revista, Belo Horizonte, v. 27, n. 02, p. 277-302, ago. 2011. Disponível em: 〈http://www.scielo.br/pdf/edur/v27n2/a13v27n2.pdf>. Acesso em 21 dez. 2011.

BRASIL. Ministério da Educação. Secretaria de Educação Especial. Política Nacional de Educação Especial na Perspectiva da Educação Inclusiva. Documento elaborado pelo grupo de trabalho nomeado pela portaria n. $^{\circ} 555 / 2007$, prorrogada pela portaria $\mathrm{n}^{\circ}$ 948/2007, entregue ao Ministro da Educação em 07 de janeiro de 2008. Inclusão: revista de educação especial. Brasília, v. 4, n. 1, p. 7-17, jan./jun. 2008. (Edição Especial).

CASSIN, Marcos. Louis Althusser: referências para pesquisa em educação. In: LOMBARDI, José Claudinei; SAVIANI, Dermeval (Orgs.). Marxismo e educação: debates contemporâneos. 2. ed. Campinas: Autores Associados; Histedbr, 2008. p. 161179.

DUARTE, Newton. Vigotski e o "aprender a aprender": crítica às apropriações neoliberais e pós-modernas da teoria vigotskiana. 2. ed. rev. e ampl. Campinas: Autores Associados, 2001.

Por que é necessário uma análise crítica marxista do Construtivismo. In: LOMBARDI, José Claudinei; SAVIANI, Dermeval (Orgs.). Marxismo e educação: debates contemporâneos. 2. ed. Campinas: Autores Associados; Histedbr, 2008. p. 203221. 
O debate contemporâneo das teorias pedagógicas. In: MARTINS, Lígia Márcia;

DUARTE, Newton (Orgs.). Formação de professores: limites contemporâneos e alternativas necessárias. São Paulo: Cultura Acadêmica, 2010. p. 33-49. Disponível em: <http://www.culturaacademica.com.br/download-livro.asp?ctl_id=113> Acesso em: 21 dez. 2011.

EIDT, Nadia Mara. Uma análise crítica dos ideários pedagógicos contemporâneos à luz da teoria de A. N. Leontiev. Educação em Revista, Belo Horizonte, v. 26, n. 2, p. 157-188, ago. 2010. Disponível em: 〈http://www.scielo.br/pdf/edur/v26n2/a08v26n2.pdf>. Acesso em: 6 set. 2012.

FONTES, Rejane de Souza. A classe hospitalar e a inclusão da criança enferma na sala de aula regular. Revista Brasileira de Educação Especial. Marília, v. 8, n. 1, p. 45-54, 2002. Disponível em: <http://educa.fcc.org.br/pdf/rbee/v08n01/v08n01a06.pdf>. Acesso em: 19 jun. 2012.

GENTILI, Pablo. Três Teses sobre a relação trabalho e educação em tempos neoliberais. In: LOMBARDI, José Claudinei; SAVIANI, Dermeval; SANFELICE, José Luís (Orgs.). Capitalismo, trabalho e educação. 3. ed. Campinas: Autores Associados; Histedbr, 2005. p. 45-59.

GRAMSCI, Antonio. Concepção dialética da história. Tradução Carlos Nelson Coutinho. 10 ed. Rio de Janeiro: Civilização Brasileira, 1995.

LEONTIEV, Alexis N. O desenvolvimento do psiquismo. Tradução Manuel Dias Duarte. Lisboa: Livros Horizonte, 1978.

LOMBARDI, José Claudinei. Educação, ensino e formação profissional em Marx e Engels. In: LOMBARDI, José Claudinei; SAVIANI, Dermeval (Orgs.). Marxismo e educação: debates contemporâneos. 2. ed. Campinas: Autores Associados; Histedbr, 2008.p. 1-38.

MARX, Karl. Teoria e processo histórico da revolução social. Tradução Florestan Fernandes. Teoria e processo histórico da revolução social. In: FERNANDES, Florestan (Org.). Marx, Engels: História. 3. ed. São Paulo: Ática, 1989. p. 231-235.

Para a crítica da filosofia do Direito de Hegel: Introdução. Tradução de Artur Morão. Covilhã: LusoSofia, 2008. (Coleção Textos Clássicos LusoSofia). Disponível em: <http://www.lusosofia.net/textos/marx_karl_para_a_critica_da_filosofia_do_direito_de_he gel.pdf>. Acesso em 20 de dez. 2011.

MARX, Karl; ENGELS, Friedrich. A ideologia alemã. Tradução Luis Claudio de Castro e Costa. 3.ed. São Paulo: Martins Fontes, 2007.

Textos sobre educação e ensino. Campinas: Navegando, 2011. Disponível em: <http://eventohistedbr.com.br/editora/wp-content/uploads/2011/09/ marx_engels_educacao_ensino_navegando_ebook.pdf>. Acesso em: 26 dez. 2011. 
OLIVEIRA, Anna Augusta Sampaio de; POKER, Rosimar Bortolini. Educação inclusiva e municipalização: a experiência em educação especial de Paraguaçu Paulista. Revista

Brasileira de Educação Especial. Marília, v. 8, n. 2, p. 233-244, jul./dez. 2002.

Disponível em:

<http://www.abpee.net/homepageabpee04_06/artigos_em_pdf/revista8numero2pdf/7olivei ra_poker.pdf $>$. Acesso em: 19 jun. 2012.

SANFELICE, José Luís. Escola pública e gratuita para todos: inclusive para os "deficientes mentais". Cadernos CEDES, Campinas, n. 23, p. 29-37, 1989. (Edição Especial).

SAVIANI, Dermeval. Educação: do senso comum à consciência filosófica. 14. ed. rev. Campinas: Autores Associados, 2002.

Pedagogia Histórico-Crítica: primeiras aproximações. 8. ed. rev. e ampl. Campinas: Autores Associados, 2003.

Escola e Democracia. 41. ed. rev. Campinas: Autores Associados, 2009a.

Formação de professores: aspectos históricos e teóricos do problema no contexto brasileiro. Revista Brasileira de Educação, Rio de Janeiro, v. 14, n. 40, p. 143-155, jan./abr. 2009b. Disponível em: 〈http://www.scielo.br/pdf/rbedu/v14n40/v14n40a12.pdf>. Acesso em: 16 fev. 2012.

SELAU, Bento. Inclusão na sala de aula. 2. ed. São Luiz: Edufma, 2010.

VYGOTSKI, Lev Semiónovic. Obras escogidas: fundamentos de defectología. Tradução Julio Guillermo Blank. Madrid: Visor, 1997. Tomo V.

Notas

${ }^{1}$ Este ensaio, com alterações e supressões, retoma reflexões desenvolvidas em minha dissertação de mestrado (BEZERRA, 2012), a qual contou com apoio financeiro da Capes, quando de seu desenvolvimento no Programa de Pós-Graduação em Educação da Universidade Estadual de Mato Grosso do Sul, unidade universitária de Paranaíba. Originalmente, o texto ora apresentado, em uma tiragem limitada e bastante localizada, foi publicado, com o mesmo título, nesta coletânea: NOZU, Washington Cesar Shoiti; LONGO; Marcelo Pereira; BRUNO, Marilda Moraes Garcia. (Orgs.). Direitos Humanos e Inclusão: discursos e práticas sociais. Campo Grande: Editora UFMS, 2014. p. 175-193. Assim, visando à sua maior divulgação, haja vista o potencial de alcance dos periódicos on line, bem como o desejo de tornar mais difundido esse trabalho, optei por também colocá-lo neste lugar. Vale ressaltar que me foi concedida autorização expressa da Editora UFMS para tal fim.

${ }^{2}$ Professor na Universidade Federal de Mato Grosso do Sul, campus de Naviraí (UFMS/CPNV), nos cursos de Pedagogia e Ciências Sociais. Mestre em Educação e pedagogo pela Universidade Estadual de Mato Grosso do Sul, unidade de Paranaíba (Uems). Doutorando em Educação pela Universidade Federal da Grande Dourados (UFGD). E-mail: gfbezerra@gmail.com

${ }^{3}$ Em minha dissertação de mestrado (BEZERRA, 2012), o leitor poderá conferir as referências bibliográficas de outros trabalhos de minha (co)autoria sobre a temática da inclusão, em especial no que tange à inclusão escolar de pessoas com deficiência. Tais referências não são aqui disponibilizadas por economia de espaço.

4 Considera-se público-alvo da educação especial os alunos com deficiência, transtornos globais de desenvolvimento e altas habilidades/superdotação (BRASIL, 2008). 
5 A esse respeito, o leitor poderá retomar as discussões realizadas em minha dissertação de mestrado (BEZERRA, 2012), na qual encontrará, também, referências bibliográficas que remetem aos conceitos de teoria do capital humano, neoliberalismo, toyotismo e suas interfaces com a atual proposta inclusivista.

${ }^{6}$ Entendo que Duarte (2008) esteja se referindo à ideologia contra-hegemônica, articulada organicamente em torno dos interesses populares, na acepção gramsciana do termo ideologia (Cf. GRAMSCI, 1995).

${ }^{7}$ É preciso ressaltar que a educação estatal, na acepção marxiana, “[...] deve prescindir dos mecanismos de controle que hoje, por exemplo, vislumbramos por meio de políticas educacionais ditatoriais, cujos mandatários estão a representar instituições financeiras expressivas dos interesses capitalistas. Almeja-se com isso assegurar a abolição do monopólio minoritário e classista da cultura, do conhecimento, da literatura, das artes, da filosofia e da ciência” (LOMBARDI, 2008, p. 21).

${ }^{8}$ Em nota de rodapé, Barroco (2007a, p. 11) assim define, resumidamente, Defectología: "Termo utilizado por Vigotski e outros autores soviéticos no início do século XX, refere-se à área de estudos teóricos e de intervenção relativa ao que hoje se conhece como Educação Especial."

${ }^{9}$ As escolas comuns e públicas, com a política de inclusão escolar, têm se organizado de modo a ofertar Atendimento Educacional Especializado (AEE) aos estudantes considerados público-alvo da educação especial no contraturno, em salas de recursos multifuncionais. Assim, permanece a dicotomia entre ensino comum e especial, situação que têm desencadeado outras formas de estigmatização e exclusão na escola inclusiva.

${ }^{10}$ Citação disponível em: <http://www.vermelho.org.br/mg/noticia.php?id_secao=76\&id_noticia=119459>.

Recebido: julho-15 Aprovado: setembro-16 